\title{
Managing obesity in adults in primary care
}

\author{
Gilles Plourde MD PhD, Denis Prud'homme MD MSc
}

$\mathrm{D}$ espite the availability of guidelines ${ }^{1}$ and articles recommending strategies for managing obesity, the successful prevention and treatment of this condition remains an unmet goal in most clinical practices. Even though evidence suggests that patients are considerably more likely to lose weight when they are advised to do so by their primary care physicians, most patients who are clinically obese do not receive weight-loss counselling in primary care. ${ }^{2-4}$ Patients may be told to lose weight, but they may not be given advice on how to do so successfully. There is an urgent need to find simple, effective strategies for improving weightloss counselling in clinical practice.

According to the most recent Canadian Health Measures Survey (2007-2009), about $62.1 \%$ of the adult population is overweight (body mass index $[\mathrm{BMI}] \geq 25 \mathrm{~kg} / \mathrm{m}^{2}$ ) and $24.3 \%$ is obese $\left(\mathrm{BMI} \geq 30 \mathrm{~kg} / \mathrm{m}^{2}\right){ }^{5}$ The reasons for obesity are multiple, including genetic, metabolic, familial and socioeconomic factors, but the principal cause is a positive energy balance secondary to an excess intake of calories with or without low energy expenditure. Obesity can develop at any age, but the prevalence is highest in middle age and typically declines after the age of 65 years. ${ }^{6}$

In 2008 , the economic cost of obesity in Canada was estimated at $\$ 4.6$ billion, up about $19 \%$ from $\$ 3.9$ billion in 2000 . When the costs associated with 18 chronic diseases linked to obesity are factored into the estimate, this cost increases to almost $\$ 7.1$ billion. ${ }^{6}$ Obesity is associated with increased risks for chronic medical conditions such as hypertension, type 2 diabetes, dyslipidemia, coronary artery disease, osteoarthritis, obstructive sleep apnea, depression, gastrointestinal reflux disease, gallbladder disease, hepatic steatosis and colon, endometrial, prostate and breast cancers. ${ }^{5,6}$

No single approach will work for every patient with obesity. Thus, an armamentarium of counselling strategies (aimed at changing dietary and physical activity habits), medications or referral to surgery may be required in caring for these patients. ${ }^{4}$ The objective of this review is to present the most recent and strongest evidence-based strategies that may aid primary care physicians in improving their counselling of patients with obesity to lose weight and maintain their weight loss for the long term. Most studies in this area are observational in design with few randomized controlled trials. A summary of the evidence used in this review and definitions of evidence levels I-III are available in Box 1. Dietary, physical activity and psychological interventions were reviewed; surgical interventions will not be discussed, as a review on that topic has recently been published?

\section{Is the patient overweight or obese?}

There are several methods for assessing obesity and overweight, but the two most commonly used in clinical practice are body mass index (BMI) and waist circumference (Box 2). ${ }^{8}$ Body mass index is a reliable determinant of adiposityrelated health risk; waist circumference measures abdominal (central) body fat and is strongly correlated with increased risk for diabetes, hypertension, dyslipidemia, metabolic syndrome and other obesity-related illnesses and death. ${ }^{8}$

Interpreting the relationship between BMI or waist circumference and health risk in people older than 65 years of age requires caution. Health risk may not be increased in elderly people who are overweight, whereas an increased health risk may occur with a low BMI. ${ }^{8}$ Although body-weight classification is intended for use in all ethnic and racial groups in Canada, there are limitations in applying it to nonwhite Canadians. Among Asian Canadians, lower BMI cut-offs for overweight $\left(>23 \mathrm{~kg} / \mathrm{m}^{2}\right)$ and obese $\left(>27 \mathrm{~kg} / \mathrm{m}^{2}\right)$ may be warranted. ${ }^{8}$ Health risk appears to be lower for a given range of BMI and waist circumference among black Canadians than among

\section{KEY POINTS}

- Measuring waist circumference can identify patients with abdominal obesity who may have a normal body mass index, yet be at high risk for obesity-related illnesses and death.

- Primary care physicians can successfully counsel patients who are overweight or obese to change their dietary and physical activity habits using the " $5 \mathrm{~A}$ " model of counselling and stage-specific strategies for changing lifestyles.

- Dietary and physical activity interventions, alone or in combination, are effective for losing weight, and adding psychological interventions improves their success.

- Strategies to help patients maintain their weight loss for the long term include a high level of physical activity, a diet low in calories and fat, eating breakfast daily and self-monitoring weight. 
white Canadians, suggesting the need for higher cut-offs to identify increased health risk in this population. Further research is needed to determine the appropriateness of these cut-offs for Aboriginal adults.

The importance of measuring waist circumference is supported by the results of the 2007 2009 Canadian Measures Health Survey: 2.6\% of adults with normal weight, $35.3 \%$ of adults with overweight and $93.0 \%$ of adults with obesity had waist circumferences suggesting abdominal obesity. ${ }^{9}$ Furthermore, although BMI data suggest that $24 \%$ of Canadian adults are at high risk for obesity-related illness or death, $37 \%$ of Canadian adults are at high risk when waist circumference is taken into consideration. ${ }^{9}$ Thus, using both measures increases the threshold for identifying patients at risk for health problems (level III evidence). ${ }^{8}$ The risks for all medical conditions associated with obesity increase with

\section{Box 1: Evidence used in this review}

We conducted a literature search for publications dating from January 2006 to July 2011. We searched Medline, Embase, Scopus and the Cochrane Database of Systematic Reviews, using the following search terms: obesity, primary care, diet, physical activity, psychological counselling, weight loss and weight maintenance. We limited articles to studies involving adults that were published in either English or French. We included randomized controlled trials, systematic reviews and meta-analyses (level I evidence), as well as prospective cohort, case-control or cross-sectional studies (level II evidence). In addition, we included articles that originated from expert opinion or consensus statements (level III evidence). We identified 600 articles and the titles, abstracts and bibliographies were reviewed independently by both authors; 88 of these publications were reviewed in their entirety. We excluded articles published before January 2006 (i.e., before the publication of the Canadian guidelines ${ }^{1}$ on the management and prevention of obesity in adults and children). We placed a greater emphasis on the most recently published articles to better reflect current findings.

Box 2: Assessment of risk* to overall health using BMI and waist circumference $^{8}$

BMI

- Overweight (25.0-29.9 kg/m²): increased risk

- Obesity class I $\left(30.0-34.9 \mathrm{~kg} / \mathrm{m}^{2}\right)$ : high risk

- Obesity class II $\left(35.0-39.0 \mathrm{~kg} / \mathrm{m}^{2}\right)$ : very high risk

- Obesity class III $\left(\geq 40.0 \mathrm{~kg} / \mathrm{m}^{2}\right)$ : extremely high risk

Waist circumference $\dagger$

- Men, $\geq 102 \mathrm{~cm}$ : increased risk

- Women, $\geq 88 \mathrm{~cm}$ : increased risk

Combined $\mathrm{BMI}$ and waist circumference

- Normal weight $\left(18.5-24.9 \mathrm{~kg} / \mathrm{m}^{2}\right)$ with abnormal waist circumference: increased risk

- Overweight with abnormal waist circumference: high risk

- Obesity class I with abnormal waist circumference: very high risk

Note: $\mathrm{BMI}=$ body mass index.

*Risk of obesity-related comorbidities (e.g., diabetes, hypertension, dyslipidemia, metabolic syndrome).

†As measured at the midpoint between the last rib and the iliac crest. higher BMIs and larger waist circumferences (Box 2), ${ }^{8}$ and decrease with weight loss and its long-term maintenance. ${ }^{1,6}$

\section{Which models are useful for counselling patients?}

There is strong evidence (level I) that the $5 \mathrm{~A}$ model (assess/ask, advise, agree, assist, arrange) of behavioural change, adapted from tobacco cessation interventions in clinical care, can be effective in helping patients modify their health behaviour ${ }^{10}$ and promoting physical activity. ${ }^{11,12}$ In counselling patients on weight loss, physicians routinely emphasize the "advise" component of the model; less commonly do they assess, assist or arrange. ${ }^{13}$ Box 3 describes the application of this simple mnemonic for providing dietary and physical activity counselling to patients who are overweight or obese. .,4,11,12,14-31 $^{-10}$

In a recent clinical review, ${ }^{15}$ stage-specific strategies for changing sedentary behaviours are described and can be used by physicians to provide tailored advice to patients about changing their dietary and physical activity habits according to their individual stage of change. In addition, the motivational approach to interviewing described in the same review may be useful in empowering patients to change their behaviours.

\section{Dietary interventions}

Studies, including randomized controlled trials, have attempted to compare the positive effects of specific dietary compositions on changes in weight. ${ }^{16,32,33}$ These trials suggest that dietary adherence and caloric restriction are more important than macronutrient composition in determining weight loss (level I evidence). Canadian guidelines on obesity recommend a highprotein or low-fat diet as a reasonable short-term (6-12 mo) treatment option for adults with obesity (level III evidence). ${ }^{1}$

Prescribing such diets in clinical practice can be challenging because physicians may not have the time or expertise to provide appropriate advice on dietary composition. The guidelines propose that an optimal dietary plan be developed, preferably by a registered dietician (level III evidence). ${ }^{1}$ According to a recent meta-analysis, dietary counselling for patients with obesity can result in a mean change in weight of -1.9 (95\% confidence interval $[\mathrm{CI}]-2.3$ to -1.5 ) BMI units $(6 \%$ of initial body weight [5 kg]) at 12 months compared with usual care. ${ }^{34}$ However, the authors also found that weight losses diminished over time, emphasizing the importance of providing long-term counselling to patients. 


\section{Physical activity interventions}

A Cochrane review of 43 randomized controlled trials showed that exercise-only interventions can result in a marginal mean weight loss of 2.03 (95\% CI 2.82 to 1.23 ) $\mathrm{kg}$ compared with no treatment. ${ }^{27}$ Interventions that combine exercise and diet resulted in a greater reduction in weight than dietary interventions alone (a change of $-1.0 \mathrm{~kg}, 95 \% \mathrm{CI}-1.3$ to $-0.7 \mathrm{~kg}$ ), and increasing the intensity of the exercise increased weight loss by 1.5 (95\% CI 2.3 to 0.7$) \mathrm{kg}$ (level I evidence). ${ }^{27}$ The Canadian guidelines recom- mend 30 minutes of physical activity of moderate intensity per day, increasing to 60 minutes per day as part of an overall weight-loss program, which should be both sustainable and tailored to the individual (level III evidence). ${ }^{1}$ Applicable strategies for physical activity counselling in obesity using the $5 \mathrm{~A}$ model are presented in Box 3., ${ }^{2,411,12,14-31}$

\section{Psychological interventions}

Psychological interventions refer to the principles and techniques used to change a patient's behav-

\section{Box 3: Counselling on dietary and physical activity interventions using the 5A model ${ }^{2,4,11,12,14-31}$}

Assess:

- The severity of obesity, using body mass and waist circumference (Box 2), and conduct clinical and laboratory investigations for comorbidities (treat comorbidities and other health risks, if present)

- Dietary patterns using REAP

- Health risks to physical activity using the PAR-Q; if risks are identified, ensure ongoing management of the comorbidity

- Current level of physical activity, making sure to note the amount of time spent in sedentary activities each week

- The patient's perceived ability to participate in dietary and physical activity interventions and the availability of social support

- The patient's readiness for change and adjust counselling accordingly

- Whether the patient is a candidate for pharmacotherapy or surgery; if yes, review the options

Advise:

- Identify the caloric deficit needed for weight loss

- Provide information on the various types of diets (i.e., the low glycemic index diet for patients with type 2 diabetes, the DASH diet for patients with hypertension), ease of adherence and the importance of self-monitoring

- Use recommendations from Canada's Food Guide regarding portion sizes, the variety of foods to eat each day, and limiting the intake of foods and beverages high in calories, fat, sugar or sodium (level III evidence)

- Highlight the importance of reading food labels to make healthier food purchases by choosing products that contain fewer calories and less fat, sugar and sodium (level II evidence)

- Educate the patient on limiting meals at restaurants, selecting healthy options when dining out, consuming more fruits and vegetables, avoiding large portion sizes and eating foods with low energy density (level III evidence)

- Provide information on obesity and its associated health risks, which can be reduced through increasing physical activity with or without weight loss (level I evidence)

- Highlight the importance of substituting sedentary activities for low- to moderate-intensity physical activity (level III evidence)

- Plan a step-wise increase in activity for previously sedentary patients (e.g., starting with short sessions [5-10 min] and increasing gradually to the desired level of physical activity) (level III evidence)

Agree:

- Define success in realistic and achievable terms, which will help maintain patient motivation

- Emphasize that a modest weight loss of 5\%-10\% of initial body weight can have major benefits to health (level III evidence)

Assist:

- Help patients overcome identified barriers

- Provide self-help materials based on patient interest and need

- Teach weight-maintenance skills, such as self-monitoring; teaching can be effective particularly when delivered face-to-face (level I evidence)

- Review food and physical activity diaries on follow-up and reassess if initial goals are not met

- Provide patients with a list of local community resources (e.g., local gyms, walking groups, parks)

- Help patients identify strategies to improve adherence, such as wearing a pedometer for record keeping or working out with a friend

- Help the patient adopt and maintain an active lifestyle

Arrange:

- Provide follow-up with physicians and other health professionals when available (level I evidence); follow-up is associated with better maintenance of behaviour change, and can take the form of a brief telephone call, postcard or letter, or a referral to a dietitian, kinesiologist, nurse practitioner or psychologist

Note: $\mathrm{BMI}=$ body mass index, DASH = dietary approaches to stop hypertension, REAP = rapid eating and activity assessment for participants (a questionnaire that takes approximately 10 minutes to complete, which can be done in the waiting room), PAR-Q = physical activity readiness questionnaire (a short health risk screening tool that can be completed in the waiting room). 
iours and habits to improve the efficacy of dietary and physical activity interventions. A total of 36 randomized controlled trials involving 3495 patients were included in a recent meta-analysis ${ }^{26}$ that showed behavioural therapy was significantly associated with greater reductions in weight compared with placebo when assessed as a stand-alone weight-loss strategy (a change of $-2.5 \mathrm{~kg}, 95 \% \mathrm{CI}$ -1.7 to $-3.3 \mathrm{~kg}$ ). When behavioural therapy was combined with diet or exercise interventions, then compared with diet and exercise in combination, the intervention that incorporated behavioural therapy resulted in a greater weight reduction. Studies were heterogeneous; however, most favoured combining behavioural therapy with dietary and exercise interventions to improve weight loss. Increas-

Box 4: Strategies for maintaining long-term weight loss ${ }^{39-42}$

Engage in a high level of physical activity

Women in the National Weight Control Registry* expended

$2545 \mathrm{kcal} /$ week in physical activity; men expended $3293 \mathrm{kcal} / \mathrm{week}$ ( $1 \mathrm{~h} /$ day) (level II evidence).

\section{Eat a diet low in calories and fat}

Most participants in the registry consumed low-fat and low-calorie diets (1381 kcal/day; 24\% from fat) (level II evidence).

\section{Eat breakfast}

$78 \%$ of participants in the registry consumed breakfast daily (level II evidence)

\section{Self-monitor weight on a regular basis}

$44 \%$ of participants in the registry report weighing themselves at least once a day (level II evidence)

\section{Keep a consistent eating pattern}

Participants in the registry who reported a consistent diet across the week (59\%) were 1.5 times more likely to maintain their weight within $5 \mathrm{lbs}(2.3 \mathrm{~kg})$ by the subsequent year than participants $(39 \%)$ who dieted more strictly on weekdays (level II evidence).

\section{Catch "slips" before they turn into larger regains}

$96 \%$ of participants in registry remained less than $10 \%$ below their maximum lifetime weight, which is considered "successful" by current standards of obesity treatment (level II evidence)

*The National Weight Control Registry includes information from more than 5000 people who have lost more than 70 pounds, on average, and kept it off for an average of 6 years.

\section{Box 5: Resources for physicians and patients}

2006 Canadian clinical practice guidelines on the management and prevention of obesity in adults and children

www.cmaj.ca/content/176/8/S1.full

\section{Canada's Food Guide}

www.hc-sc.gc.ca/fn-an/alt_formats/hpfb-dgpsa/pdf/food-guide-aliment /print_eatwell_bienmang-eng.pdf

PAR-Q (physical activity readiness questionnaire)

http://uwfitness.uwaterloo.ca/PDF/par-q.pdf

REAP (rapid eating and activity asessment for participants)

http://publichealth.brown.edu/ICHP/download/REAP.pdf

DASH (dietary approaches to stop hypertension)

www.nhlbi.nih.gov/health/public/heart/hbp/dash/new_dash.pdf ing the intensity of the behavioural intervention significantly increased weight loss (change in weight of $-2.3 \mathrm{~kg}, 95 \% \mathrm{CI}-1.4$ to $-3.3 \mathrm{~kg}$ ). Cognitivebehavioural therapy, when combined with a diet and exercise intervention, resulted in greater weight loss than diet or exercise alone (change in weight of $-4.9 \mathrm{~kg}, 95 \% \mathrm{CI}-7.3$ to $-2.4 \mathrm{~kg})$.

\section{When should drugs or surgery be considered?}

Pharmacologic treatment of obesity has changed very little recently. The Canadian guidelines recommend pharmacologic treatments for the management of obesity for patients who do not respond to lifestyle interventions alone, especially if bariatric surgery is not an option (level III evidence). ${ }^{1}$ The American College of Physicians' guidelines for the management of obesity in primary care recommend that pharmacotherapy be considered for patients with a BMI of $30 \mathrm{~kg} / \mathrm{m}^{2}$ or more who have been unable to achieve weight-loss goals through diet and exercise. Patients with a BMI of $27.0-29.9 \mathrm{~kg} / \mathrm{m}^{2}$ and an obesity-related comorbidity may also benefit from pharmacologic treatment. ${ }^{35}$

Orlistat, a gastrointestinal and pancreatic lipase inhibitor that blocks the absorption of $30 \%$ of ingested fat, is the only available long-term drug therapy for obesity in Canada. A Cochrane metaanalysis of 16 randomized controlled trials involving 10631 patients has shown that, compared with placebo, Orlistat reduced weight by 2.9 (95\% CI 2.5 to 3.2$) \mathrm{kg}$. Patients taking Orlistat were also significantly more likely to lose $5 \%-10 \%$ of their initial body weight. ${ }^{36}$

Surgical intervention is an option for carefully selected patients with clinically severe obesity (BMI $\geq 40 \mathrm{~kg} / \mathrm{m}^{2}$, or BMI $\geq 35 \mathrm{~kg} / \mathrm{m}^{2}$ with comorbid conditions) who have been unable to lose weight using other methods and who are at high risk for obesity-associated illness or death. ${ }^{1,7}$ It may be of particular benefit to those patients with diabetes. ${ }^{37,38}$

\section{How can patients maintain their weight loss?}

It can be difficult for patients to maintain their weight loss for the long term. The National Weight Control Registry includes information from more than 5000 people who have lost more than 70 pounds ( $31.8 \mathrm{~kg}$ ), on average, and kept it off for an average of six years. This resource provides insight into possible strategies that could be incorporated into clinical practice (Box 4)..$^{39-42}$ 
Research shows that greater self-reported physical activity is the strongest correlate of longterm weight loss, followed by treatment attendance and consumption of meal replacements (level I evidence). ${ }^{42}$ Intensive behavioural modification has also been shown to promote long-term maintenance of weight loss. Weight-loss maintenance comparable with that after bariatric surgery can be accomplished through nonsurgical methods with intensive behavioural modification (level I evidence) ${ }^{30}$ surgical participants reported less physical activity, greater consumption of fast foods and fat, less dietary restraint and higher levels of depression and stress. ${ }^{40}$

It is important to note that lack of weight loss does not imply lack of benefit. There is emerging evidence that a lifestyle-modification program characterized by an increase in physical activity and a balanced diet can still reduce the risk of obesity-related comorbid conditions despite minimal or no weight loss (level I evidence), ${ }^{4,14,16,43}$

\section{How can we improve the manage- ment of obesity in primary care?}

Physicians have identified many barriers to managing obesity, including a lack of time, resources and knowledge. In a study by Jay and colleagues ${ }^{44} 45 \%$ of physicians said they did not feel qualified to treat obesity. According to the Strategies to Overcome and Prevent Obesity Alliance, ${ }^{45} 72 \%$ of primary care physicians surveyed said that no one in their practice was trained to deal with weight-related issues. In one primary care setting, BMI was calculated for only $64 \%$ of adults during the first visit. ${ }^{46}$ For patients who were overweight or obese, only $49 \%$ received education on weight loss, $50 \%$ on diet, and $41 \%$ on exercise.

Strategies to improve the care of patients with obesity in primary care include regularly measuring BMI and waist circumference and the use of prompts and reminders to calculate BMI and measure waist circumference..$^{4,14,16,47,48}$ In a randomized controlled trial, ${ }^{48}$ patients who had a prompt to calculate BMI in their electronic medical record were significantly more likely than patients without a prompt to receive a diagnosis of obesity $(16.6 \%$ v. $10.7 \% ; p=0.016)$ and referrals for dietary $(14.0 \%$ v. $7.3 \%, p=0.002)$ and physical activity $(12.1 \%$ v. $7.1 \%, p=0.016)$ interventions. Furthermore, one trial found that reminders to perform specific preventive actions could change practice, resulting in a significant reduction in weight among men (by $11.2 \mathrm{~kg}, 95 \%$ CI 1.7 to $20.7 \mathrm{~kg}$, at 1 year). ${ }^{47}$

Compared with standard care, educational interventions aimed at changing the behaviour of health care professionals to promote weight reduction have been shown to be effective (level I evidence). Box 5 includes resources for primary care physicians.

\section{Unanswered questions}

Adult obesity remains a public health concern in Canada. Primary care physicians are in an influential position to provide weight-loss counselling, which can be successfully done using the $5 \mathrm{~A}$ model of behavioural change and stagespecific strategies for changing lifestyles. Clinicians can promote long-term maintenance of weight loss using the strategies presented in Box $4{ }^{39-42}$ To complete this intervention, a sixth "A" should be added to the mnemonic: advocate - that is, to advocate for environmental and policy changes that support healthy eating and physical activity.

However, there are questions for which we do not have complete answers. The impact of implementing a curriculum for counselling in obesity for residents deserves future research. In one nonrandomized controlled trial by Jay and colleagues ${ }^{49}$ residents who received training in obesity counselling that consisted of case studies, role playing, behaviour assessment, goal setting and motivational interviewing delivered a higher quality of counselling. However, this improvement was only noted once patient, physician and visit characteristics were taken into consideration. In addition, whether there is a need to provide recommendations by class of obesity (as defined in Box 2) needs to be assessed in future research.

It is well documented that being overweight or obese during childhood and adolescence increases the risk of being overweight or obese as an adult. Obesity in children is an important early risk factor for adult illness and death related to cardiovascular and other chronic diseases..$^{50}$ That increased risk persists even if adolescents who were obese lose the excess weight during adulthood. Future research is needed to assess the effect, if any, that the transfer of obesity from childhood/adolescence to adulthood has on the success of interventions for obesity in later life.

\section{References}

1. Lau DCW, Douketis JD, Morrison KM, et al. 2006 Canadian clinical practice guidelines on the management and prevention of obesity in adults and children [summary]. CMAJ 2007;176:S1-13.

2. Bardia A, Holtan SG, Stezak JM, et al. Diagnosis of obesity by primary care physicians and impact on weight management. Mayo Clin Proc 2007;82:927-32.

3. Rodondi N, Humair JP, Ghali WA, et al. Counselling overweight and obese patients in primary care: a prospective cohort study. Eur J Cardiovasc Prev Rehabil 2006;13:222-8.

4. Kolasa KM, Collier DN, Cable K. Weight-loss strategies that really work. J Fam Pract 2010;59:378-85. 
5. Shields M, Tremblay MS, Laviolette M, et al. Fitness of Canadian adults: results from the 2007-2009 Canadian Health Measures Survey. Health Rep 2010;21:21-35.

6. Public Health Agency of Canada. Obesity in Canada: a joint report from the Public Health Agency of Canada and the Canadian Institute for Health Information. Ottawa $(\mathrm{ON})$ : The Agency; 2010. p. 1-54. Available: www.phac-aspc.gc.ca/hp-ps/hl -mvs/oic-oac/assets/pdf/oic-oac-eng.pdf (accessed 2011 Aug. 1).

7. Karmali S, Stoklossa CJ, Sharma A, et al. Bariatric surgery. Can Fam Physician 2010;56:873-9.

8. Douketis JD, Paradis G, Keller H, et al. Canadian guidelines for body weight in adults: application in clinical practice to screen for overweight and obesity and to assess disease risk. CMAJ 2005;172:995-8.

9. Janssen I, Shields M, Craig CL, et al. Prevalence and secular changes in abdominal obesity in Canadian adolescents and adults, 1981 to 2007-2009; prevalence of abdominal obesity in Canada. Obes Rev 2011;12:397-405.

10. Whitlock EP, Orleans T, Pender N, et al. Evaluating primary care behavioral counseling interventions: an evidence-based approach. Am J Prev Med 2002;22:267-84.

11. Meriwether RA, Lee JA, Schroeder Lafleur A, et al. Physica activity counselling. An Fam Physician 2008;77:1029-1136, 1138.

12. Beaulac J, Carlson AM, Boyd RJ. Counseling on physical activity to promote mental health: practical guidelines for family physicians. Can Fam Physician 2011;57:399-401.

13. Alexander SC, Cox ME, Boling Turer CL, et al. Do the five A's work when physicians counsel about weight loss. Fam Med 2011;43:179-84.

14. Plourde G. Treating obesity: lost cause or new opportunity? Can Fam Physician 2000;46:1806-13.

15. Plourde G, Marineau JM. Reducing sedentary behaviours in obese patients. If they won't exercise more - try to make them sit less. Parkhurst Exchange 2011;19:63-71.

16. Hussain SS, Bloom SR. The pharmacological treatment and management of obesity. Postgrad Med 2011;123:34-44.

17. Rutledge T, Groesz LM, Linke SE, et al. Behavioral weight management for the primary care provider. Obes Rev 2011;12: e290-7.

18. Gans KM, Risica PM, Wylie-Rosett J, et al. development and evaluation of the nutrition component of the Rapid Eating and Activity Assessment for Patients (REAP): a new tool for primary care providers. J Nutr Educ Behav 2006:38:286-92.

19. Svetkey LP, Stevens VJ, Brantley PI, et al. Comparison of strategies for sustaining weight loss: the weight-loss maintenance randomized controlled trial. JAMA 2008;299:1139-48.

20. Eating well with Canada's food guide. Ottawa (ON): Health Canada; 2007 Available: www.hc-sc.gc.ca/fn-an/alt_formats/hpfb -dgpsa/pdf/food-guide-aliment/print_eatwell_bienmang-eng.pdf (accessed 2011 Aug. 1).

21. Hardcastle S, Taylor A, Bailey M, et al. A randomised controlled trial on the effectiveness of a primary health care based counselling intervention on physical activity, diet and CHD risk factors. Patient Educ Couns 2008;70:31-9.

22. Molenaar EA, Van Ameijden EJ, Vergouwe Y, et al. Effect of nutritional counselling and nutritional plus exercise counselling in overweight adults: a randomized trial in multidisciplinary primary care practice. Fam Pract 2010;27:143-50

23. Tsai AG, Wadden TA, Rogers MA, et al. A primary care intervention for weight loss: results of a randomized controlled pilot study. Obesity (Silver Spring) 2010;18:1614-8.

24. Counterweight Project Team. Evaluation of the Counterweight Programme for obesity management in primary care: a starting point for continuous improvement. Br J Gen Pract 2008;58: 548-54.

25. Mozaffarian D, Hao T, Rimm EB, et al. Changes in diet and lifestyle and long-term weight gain in women and men. $N$ Engl J Med 2011;364:2392-404

26. Shaw K, O'Rourke P, Del Mar C, et al. Psychological interventions for overweight or obesity. Cochrane Database Syst Rev 2005; 1:CD003818.

27. Shaw K, Gennat HC, O'Rourke P, et al. Exercise for overweight or obesity. Cochrane Database Syst Rev 2006;1:CD003817.

28. Canadian Society for Exercise Physiology. Physical Activity Readiness Questionnaire. PAR-Q and you. Ottawa (ON): The Society; 2002 Available: http://uwfitness.uwaterloo.ca/PDF/par-q .pdf (accessed 2011 Aug. 1).

29. Haskell WL, Lee IM, Pate RR, et al. Physical activity and public health: updated recommendations for adults from the American College of Sports Medicine and the American Heart Association. Circulation 2007;116:1081-93.

30. Ross R, Bradshaw AJ. The future of obesity reduction: beyond weight loss. Nat Rev Endocrinol 2009;5:319-25.

31. Janiszewski PM, Ross R. Physical inactivity in the treatment of obesity: beyond body weight reduction. Appl Physiol Nutr Metab
$2007 \cdot 32 \cdot 512-22$

32. Alhassan S, Kim S, Bersanim A, et al. Dietary adherence and weight loss success among overweight women: results from the A to Z weight loss study. Int J Obes (Lond) 2008;32:985-91.

33. Sacks FM, Bray GA, Carey VJ, et al. Comparison of weight-loss diets with different composition of fat, protein and carbohydrates. N Engl J Med 2009;360:859-73.

34. Dansinger ML, Tatsioni A, Wong JB, et al. Meta-analysis: the effect of dietary counseling for weight loss. Ann Intern Med 2007; 147:41-50.

35. Snow V, Barry P, Fitterman N, et al. Pharmacologic and surgical management of obesity in primary care: a clinical practice guideline from the American College of Physicians. Ann Intern Med 2005; 142:525-31.

36. Padwal R, Li SK, Lau DC. Long-term pharmacotherapy for obesity and overweight. Cochrane Database Syst Rev 2007;(4): CD004094.

37. Schauer PR, Kashyap SR, Wolski K, et al. Bariatric surgery versus intensive medical therapy in obese patients with diabetes. $N$ Engl J Med 2012;366:1567-76.

38. Mingrone G, Panunzi S, De Gaetano A, et al. Bariatric surgery versus conventional medical therapy for type 2 diabetes. $N$ Engl J Med 2012;366:1577-85

39. Phelan S, Wyatt HR, Hill JO, et al. Are the eating and exercise habits of successful weight losers changing? Obesity (Silver Spring) 2006;14:710-6.

40. Butryn ML, Phelan S, Hill JO, et al. Consistent self-monitoring of weight: a key component of successful weight loss maintenance. Obesity (Silver Spring) 2007;15:3091-6.

41. Bond DS, Phelan S, Leahey TM, et al. Weight loss maintenance in successful weight losers: surgical versus non-surgical methods. Int J Obes (Lond) 2009;33:173-80.

42. Wadden TA, West DS, Neiberg R, et al. One-year weight losses in the Look AHEAD Study: factors associated with success. Obesity (Silver Spring) 2009;17:713-22.

43. Pryke R, Docherty A. Obesity in primary care: evidence for advising weight constancy rather than weight loss in unsuccessful dieters. Br J Gen Pract 2008;58:112-7.

44. Jay M, Kalet A, Ark T, et al. Physician's attitudes about obesity and their association with competency and specialty: a crosssectional study. BMC Health Serv Res 2009;9:106.

45. STOP Obesity Alliance. STOP Obesity Alliance surveys show doctors, patients share role in weight loss, but ask, now what? Washington (DC): George Washington University: the Alliance; 2010 Available: www.biotechmashup.com/beta/Biology/STOP_Obesity _Alliance_surveys_show_doctors_patients_share_role_in_weight _loss_but_ask_now_what (accessed 2012 Apr. 23).

46. Boardley D, Sherman C, Ambrosetti L, et al. Obesity evaluation and intervention during family medicine well visits. J Am Board Fam Med 2007;20:252-7.

47. Flodgren G, Deane K, Dickinson HO, et al. Interventions to change the behaviour of health professionals and the organisation of care to promote weight reduction in overweight and obese people. Cochrane Database Syst Rev 2010;(3):CD000984.

48. Schriefer SP, Landis SE, Turbow DJ, et al. Effect of a computerized body mass index prompt on diagnosis and treatment of adult obesity. Fam Med 2009;41:502-7.

49. Jay M, Schlair S, Caldwell R, et al. From the patient's perspective: the impact of training on resident physician's obesity counseling. J Gen Intern Med 2010;25:415-22.

50. Plourde G. Preventing and managing pediatric obesity. Recommendations for family physicians. Can Fam Physician 2006;52:322-8.

Affiliations: From the Drug Safety Unit - Director's Office (Plourde), Centre for Evaluation of Radiopharmaceuticals and Biotherapeutics, Biologic and Genetic Therapies Directorate, Health Canada, Ottawa, Ont.; the School of Human Kinetics (Prud'homme), Faculty of Health Sciences, University of Ottawa, Ottawa, Ont.; and Médicine du sport (Prud'homme), Gatineau, Que.

Contributors: Gilles Plourde is the main author of this manuscript. Both authors participated in the planning, writing and revision of the manuscript and approved the final version submitted for publication.

Acknowledgements: The authors thank Ms. Sabrina Omar, Population Health Risk Assessment and Management Department, Faculty of Health Sciences, University of Ottawa, for her research and editorial assistance. The opinions expressed in this article are those of the authors and do not necessarily represent those of Health Canada. 